This item was submitted to Loughborough's Research Repository by the author.

Items in Figshare are protected by copyright, with all rights reserved, unless otherwise indicated.

\title{
The need for muscle co-contraction prior to a landing
}

PLEASE CITE THE PUBLISHED VERSION

PUBLISHER

(C) Elsevier

VERSION

AM (Accepted Manuscript)

LICENCE

CC BY-NC-ND 4.0

REPOSITORY RECORD

Yeadon, Maurice R., Mark A. King, Stephanie E. Forrester, G.E. Caldwell, and Matthew T.G. Pain. 2019. "The Need for Muscle Co-contraction Prior to a Landing". figshare. https://hdl.handle.net/2134/5830. 
This item was submitted to Loughborough's Institutional Repository (https://dspace.lboro.ac.uk/) by the author and is made available under the following Creative Commons Licence conditions.

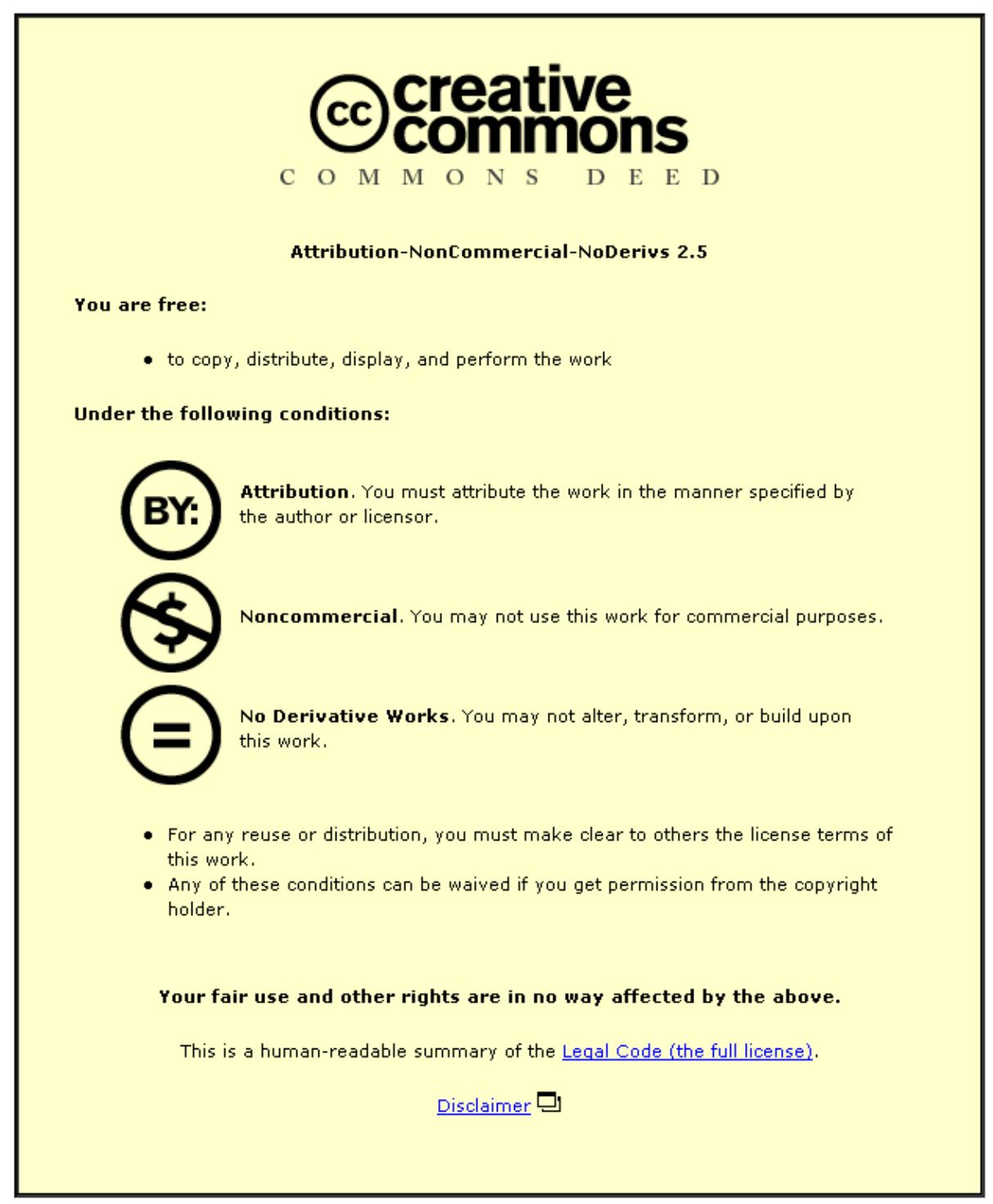

For the full text of this licence, please go to: http://creativecommons.org/licenses/by-nc-nd/2.5/ 


\title{
The need for muscle co-contraction prior to a landing
}

\author{
M.R. Yeadon ${ }^{1}$, M.A. King ${ }^{1}$, S.E. Forrester ${ }^{2}$, G.E. Caldwell ${ }^{3}$ and M.T.G. Pain ${ }^{1}$ \\ School of Sport, Exercise and Health Sciences, Loughborough University, Loughborough LE11 3TU, UK. \\ Wolfson School of Mechanical and Manufacturing Engineering, Loughborough University, Loughborough LE11 3TU, UK \\ Department of Kinesiology, University of Massachusetts, Amherst, Massachusetts, USA.
}

\begin{abstract}
In landings from a flight phase the mass centre of an athlete experiences rapid decelerations. This study investigated the extent to which co-contraction is beneficial or necessary in drop landings, using both experimental data and computer simulations. High speed video and force recordings were made of an elite martial artist performing drop landings onto a force plate from heights of $1.2 \mathrm{~m}, 1.5 \mathrm{~m}$ and $1.8 \mathrm{~m}$. Matching simulations of these landings were produced using a planar 8-segment torque-driven subject-specific computer simulation model. It was found that there was substantial co-activation of joint flexor and extensor torques at touchdown in all three landings. Optimisations were carried out to determine whether landings could be effected without any co-contraction at touchdown. The model was not capable of landing from higher than $1.05 \mathrm{~m}$ with no initial flexor or extensor activations. Due to the force-velocity properties of muscle, co-contraction with net zero joint torque at touchdown leads to increased extensor torque and decreased flexor torque as joint flexion velocity increases. The same considerations apply in any activity where rapid changes in net joint torque are required, as for example in jumps from a running approach.
\end{abstract}

\section{INTRODUCTION}

In activities such as running, running jumps and drop landings the mass centre has a velocity component towards the foot at initial contact with the ground. During the contact phase this radial velocity decreases to zero, as the mass centre to foot distance reaches a minimum, and subsequently reverses direction (Dapena and Chung, 1988). In such cases large reaction forces must be applied at the feet in order to decelerate the mass centre over a short distance.

In high jumping takeoffs, ground reaction forces typically exceed 8 bodyweights (Deporte and Van Gheluwe, 1989) while in gymnastics landings, peak forces can be as high as 14.4 bodyweights (Panzer et al., 1988). Drop jumps and landings have dynamic initial conditions which result in greater peak loads and loading rates than in, for example, counter-movement jumps which start from static postures (Bobbert et al., 1986). For landings with a given initial vertical velocity, muscular considerations impose a limit to both the distance and time the mass centre can descend before reaching zero vertical velocity at its minimum height, with maximal possible deceleration time necessarily decreasing as the initial velocity increases (Minetti et al., 1998). Shorter contact times are associated with higher torques at the knee and ankle in drop jumps (Bobbert et al., 1986) and knee joint torques exhibit the largest increases for greater drop landing heights (McNitt-Gray, 1993).

In such movements with high initial velocities the challenge for the musculo-skeletal system is to produce high joint extensor torques soon after contacting the ground. McNitt-Gray (1993) reported times of less than $50 \mathrm{~ms}$ for extensor torques to peak in drop landings whereas the rise times for the enervation of leg muscles in squat jumps are more than $100 \mathrm{~ms}$ (Bobbert and Zandwijk, 1999). Moreover the transformation from enervation to muscle force is not instantaneous due to contractile and series elastic component interactions (Caldwell, 1995). If the knee extensors are not activated prior to contact then the relatively high force rise time will be problematic for the rapid development of torque. If the knee extensors alone are active prior to contact, the knee joint will extend rapidly under 
only inertial loading, placing the knee in an inappropriate and possibly dangerous position for landing. Co-contracting the knee extensors and flexors prior to contact will enable the extensors to be active at touchdown without there being a large net extensor torque. There is evidence of such co-contraction prior to initial contact in drop landings (Minetti et al., 1998; Kellis et al., 2003) but this finding is not universal (McNitt-Gray, 1993). This paper will investigate the extent to which co-contraction is beneficial or necessary in drop landings, using both experimental data and a computer simulation model.

\section{METHODS}

\section{Simulation model}

A subject-specific computer simulation model was used to investigate technique used in drop landing performances from three heights. The planar 8-segment model was constructed using Autolev ${ }^{\mathrm{TM} 3}$ (Kane and Levinson, 1996) with torque drivers at the ball of the foot, ankle, knee, hip and shoulder joints and angle drivers at the elbow and neck joints (Figure 1). The torque generators comprised rotational contractile and series elastic elements, with extensors and flexors represented separately. Torque was calculated as the product of the maximum voluntary torque given kinematic conditions and an activation level between 0 and 1 . Activation of the ball, ankle, knee and hip extensors and shoulder flexors and extensors followed a ramp - plateau - ramp profile (Figure 2a) with touchdown activation levels no greater than 0.5 and ramp times of at least 70 ms (Freund and Budingen,1978; Bobbert and van Zandwijk, 1999). Activation of the ball, ankle, knee and hip flexors followed a ramp off - plateau - ramp on profile (Figure 2b) with the same initial activation and ramp constraints. Initial activation levels were further constrained to give zero net joint torque at touchdown. Thus, the four extensors and shoulder flexors each required seven parameters to define their activation profiles while the four flexors and shoulder extensors required five, giving a total of 60 activation parameters.

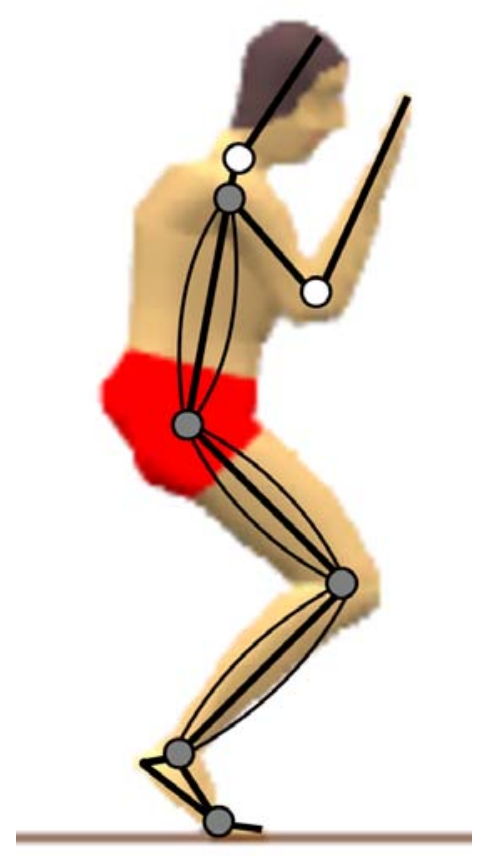

Figure 1. Eight-segment simulation model with wobbling masses within the shank, thigh and trunk segments, with torque drivers at the ball, ankle, knee, hip and shoulder (grey circles), and angle drivers at the neck and elbow (white circles). 
a

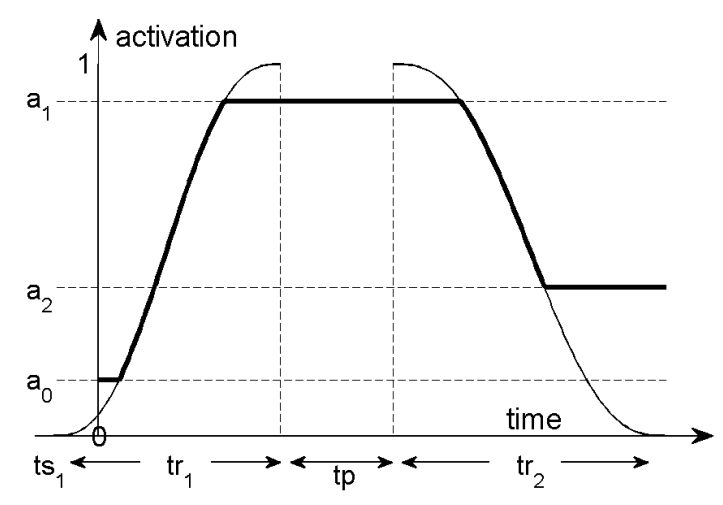

b

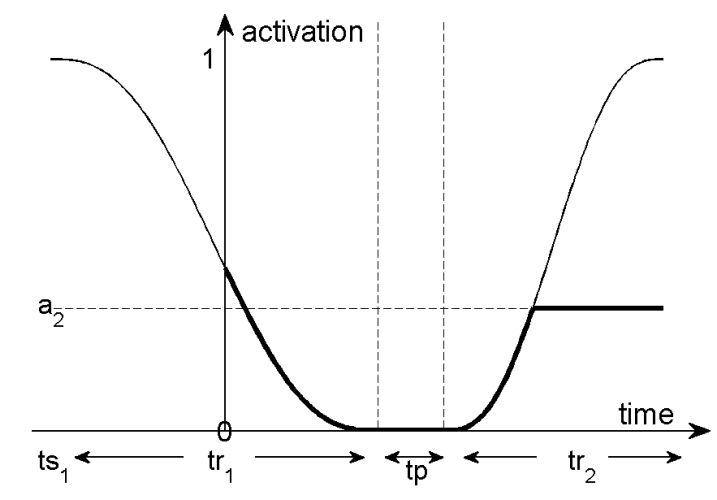

Figure 2. Activation profiles used in the model. (a) seven parameter ramp - plateau - ramp profile used for the ball, ankle, knee and hip extensors and shoulder flexor torque generators; and (b) five parameter ramp off - plateau - ramp on profile used for the ball, ankle, knee and hip flexors and shoulder extensor torque generators. Note that the initial activation level for the flexors $\left(\mathrm{a}_{0}\right)$ was set to give zero net torque at touchdown.

Soft tissue movement of the trunk, thighs and shanks was modelled using wobbling masses connected by non-linear spring-dampers to each end of the corresponding fixed rigid (bone) link (Pain and Challis, 2004). The spring-damper force, $F_{w m}$, was given by:

$$
F_{w m}=k_{w m} s^{3}-\beta_{w m} \dot{s}
$$

where $k_{w m}$ and $\beta_{w m}$ are the stiffness and damping coefficients, and $s$ and $\dot{s}$ are the stretch and stretch rate of the spring-damper.

Contact between the foot and the ground was modelled using three contact points corresponding to the toes, ball and heel. At each contact point vertical ground reaction force, $F_{y}$, was calculated from a nonlinear spring-damper function:

$$
F_{y}=-k_{a y} y+k_{b y} y^{2}-k_{a y} \beta_{y} y \dot{y}
$$


where $k_{a y}$ and $k_{b y}$ are the stiffness coefficients, $\beta_{y}$ is the damping coefficient, and $\mathrm{y}$ and $\dot{y}$ are the vertical deformation and rate of deformation relative to touchdown position. The toes and ball were assumed to have the same $k_{a y}, k_{b y}$ and $\beta_{y}$, while the heel values could be different.

All landings were toes first and during "toes only" contact it was assumed that the frictional forces determined horizontal foot movement:

$$
F_{X}=\mu F_{y} \quad \text { with } \quad \mu=\mu_{o}\left[1-\exp \left(\frac{-F_{y, T}}{60}\right)\right]
$$

where $F_{x}$ is the horizontal force, $\mu$ is the friction coefficient, and $F_{y, T}$ is the total vertical ground reaction force from all contact points (McLean et al., 2003). Once the ball had touched down, horizontal force at each point of contact was calculated from the spring-damper function:

$$
F_{x}=\left[-\beta_{x} \dot{x}_{b}-k_{x}\left(x_{b}-x_{b, t s}\right)\left(\frac{F_{y}}{F_{y, T}}\right)\right.
$$

where $k_{x}$ is the stiffness coefficient, $\beta_{x}$ is the damping coefficient, $x_{b}$ and $\dot{x}_{b}$ are the horizontal position and velocity of the ball joint and $x_{b, t s}$ is the horizontal location of the ball joint at the time it touched down.

Model parameters comprised: subject-specific inertia, strength, wobbling mass, and ground contact parameters. Model input comprised: touchdown kinematics and joint angle time histories of the free joints (elbow and head), obtained from the digitized data, and activation profiles for each torque generator, while model output comprised: time histories of ground reaction forces, joint torques and kinematics, and whole body kinematics.

\section{Parameter determination}

An elite male martial arts competitor (height $1.75 \mathrm{~m}$, mass $89 \mathrm{~kg}$, age 30 years) performed drop landings from heights of $1.2 \mathrm{~m}, 1.5 \mathrm{~m}$ and $1.8 \mathrm{~m}$. To keep the movement approximately planar, the athlete was instructed to keep his arms close to his body throughout each landing. The participant gave informed consent for the procedures, which were carried out in accordance with the protocol approved by Loughborough University Ethical Advisory Committee. Each landing was recorded at $1008 \mathrm{~Hz}$ using a Phantom 4.1 high speed video camera and a Kistler force plate. Electromyography (EMG) measurements were recorded from tibialis anterior, gastrocnemius, soleus, vastus medialis, rectus femoris, hamstrings, and gluteus maximus, using a Biovision bipolar active surface electrode system sampling at $2016 \mathrm{~Hz}$. All data collection was synchronized using a manual trigger.

Subject-specific segmental inertial parameters were determined from anthropometric measurements together with the geometric inertia model of Yeadon (1990) and segmental densities taken from Dempster (1955), adjusted to give the correct whole body mass. Individual inertia parameters for the bone and soft tissue of the shanks, thighs and trunk were calculated using the segmental inertia data in conjunction with cadaver mass ratio data from Clarys and Marfell-Jones (1986) and assuming bone to be a uniform cylinder of known length with density equal to $1100 \mathrm{~kg} \mathrm{~m}^{-3}$ (Dempster, 1955).

A two-dimensional Direct Linear Transformation procedure was used to calibrate the movement space and reconstruct the two-dimensional coordinates of nine digitized points: toe, ball, heel, ankle, knee, 
hip, shoulder and elbow joints, and the midpoint of the head. Time histories of the whole body mass centre position and joint angles of the ball, ankle, knee, hip, shoulder and elbow were obtained from the digitized coordinates and the segmental inertia data. Mass centre velocity and joint angular velocities were obtained using quintic splines (Wood and Jennings et al., 1979). The EMG data were band-pass filtered $(10-500 \mathrm{~Hz})$ using a fourth order zero-lag Butterworth filter. Root mean square (RMS) amplitudes were calculated using a $30 \mathrm{~ms}$ window, and subsequently normalized based on the maximum RMS amplitude recorded in the three landings. Subject-specific strength parameters for the ball, ankle, knee, hip and shoulder joints, were determined from maximum voluntary joint torque measurements obtained on a Cybex NORM isovelocity dynamometer. Joint torques were expressed as a function of angle and angular velocity (Yeadon et al., 2006; King et al., 2006). The complete set of subject-specific visco-elastic and friction parameters for the wobbling mass and ground contact forces was determined using optimisation to match simulations of the three landings for a common parameter set using an angle-driven version of the simulation model as described in Wilson et al. (2006).

\section{Simulations}

Matching simulations were generated for each of the three drop landings. These ran from touchdown to the time that the whole body mass centre started to rise as determined from the experimental data. The 60 activation parameters were optimized using a simulated annealing algorithm (Corana et al., 1987) which minimized a cost function, C, based on RMS difference in trunk orientation angle, RMS difference in the five torque-driven joint angles, and difference in mass centre position at the lowest point:

$C=\sqrt{\frac{1}{3}\left[(R M S \text { orientation angle })^{2}+(\text { RMS joint angles })^{2}+(R M S \Delta x, \Delta y, \Delta t \text { lowest point })^{2}\right]}$

Further optimizations for the three landing conditions were carried out with the ankle, knee and hip flexor torque generators inactive to determine if it was possible to land successfully without cocontraction and with minimal $(1 \mathrm{Nm})$ initial extensor activation. These optimizations minimized the vertical drop in whole body mass centre during the landing and were considered to be successful if the vertical drop was less than in the actual performance for the highest $(1.8 \mathrm{~m})$ landing. Additional optimizations were carried out to determine the maximum heights from which successful landings could be made with and without co-contraction. In all optimizations, to confirm that the simulated annealing algorithm had found the global optimum the process was repeated using different initial activation parameter estimates and with the parameters entered into the algorithm in a different order. These produced no further improvement in the global optima.

\section{RESULTS}

The wobbling masses in the shank, thigh and trunk model segments amounted to $68 \%$ of the total body mass (Table 1) while the stiffness coefficients $\left(k_{w m}\right)$ were $9.45 \times 10^{8}, 1.14 \times 10^{7}, 7.49 \times 10^{5} \mathrm{Nm}^{-3}$ and damping coefficients $\left(\beta_{w m}\right)$ were 631, 443, and $252 \mathrm{Nsm}^{-1}$ respectively. For the foot-ground interface the vertical stiffness parameters $k_{a y}$ and $k_{b y}$ for toes/ball were $1.99 \times 10^{5} \mathrm{Nm}^{-1}$ and zero while for the heel they were $6.81 \times 10^{4} \mathrm{Nm}^{-1}$ and $1.69 \times 10^{7} \mathrm{Nm}^{-2}$. The friction coefficient was 0.483 while the horizontal stiffness $\left(k_{x}\right)$ and damping coefficients $\left(\beta_{x}\right)$ were $3180 \mathrm{Nsm}^{-1}$ and 48,300 Nm $\mathrm{Nm}^{-1}$. 
Table 1. Segmental inertia values for the fixed and wobbling masses

\begin{tabular}{lcccc}
\hline \multicolumn{1}{c}{ segment } & $\begin{array}{c}\text { mass } \\
(\mathrm{kg})\end{array}$ & $\begin{array}{c}\text { length } \\
(\mathrm{m})\end{array}$ & $\begin{array}{c}\mathrm{CM} \\
(\mathrm{m})\end{array}$ & $\begin{array}{c}\text { MoI } \\
\left(\mathrm{kg} \mathrm{m}^{2}\right)\end{array}$ \\
\hline head + neck & 5.96 & 0.293 & 0.149 & 0.042 \\
upper arm & 5.65 & 0.268 & 0.122 & 0.040 \\
lower arm + hand & 3.88 & 0.464 & 0.165 & 0.056 \\
trunk rigid & 5.20 & 0.530 & 0.265 & 0.125 \\
trunk wobbling & 29.2 & 0.530 & 0.259 & 0.857 \\
thigh rigid & 3.12 & 0.449 & 0.225 & 0.053 \\
thigh wobbling & 24.9 & 0.449 & 0.178 & 0.428 \\
shank rigid & 2.32 & 0.421 & 0.211 & 0.035 \\
shank wobbling & 7.07 & 0.421 & 0.167 & 0.086 \\
rear foot & 2.11 & 0.171 & 0.089 & 0.004 \\
forefoot & 0.65 & 0.089 & 0.036 & 0.001 \\
\hline
\end{tabular}

Note: CM: distance of mass centre from proximal joint centre; MoI: moment of inertia about a transverse axis through the segment mass centre; each limb segment represents the combined left and right limbs.

Table 2. Comparison of matching simulations with results from video for the three landings

\begin{tabular}{|c|c|c|c|c|c|c|}
\hline drop height (m) & $\begin{array}{c}1.2 \\
\text { video }\end{array}$ & $\begin{array}{l}1.2 \\
\operatorname{sim}\end{array}$ & $\begin{array}{c}1.5 \\
\text { video }\end{array}$ & $\begin{array}{l}1.5 \\
\operatorname{sim}\end{array}$ & $\begin{array}{c}1.8 \\
\text { video }\end{array}$ & $\begin{array}{l}1.8 \\
\text { sim }\end{array}$ \\
\hline \multicolumn{7}{|l|}{ initial velocity } \\
\hline horizontal $\left(\mathrm{ms}^{-1}\right)$ & 0.90 & 0.90 & 0.91 & 0.91 & 1.03 & 1.03 \\
\hline vertical $\left(\mathrm{ms}^{-1}\right)$ & 4.72 & 4.72 & 5.34 & 5.34 & 5.91 & 5.91 \\
\hline \multicolumn{7}{|l|}{ vertical GRF } \\
\hline peak (BW) & 13.2 & 12.6 & 14.1 & 15.4 & 17.4 & 16.0 \\
\hline time (ms) & 33 & 32 & 28 & 30 & 23 & 25 \\
\hline \multicolumn{7}{|l|}{ lowest point } \\
\hline Time (ms) & 184 & 184 & 229 & 238 & 266 & 281 \\
\hline vertical drop (m) & 0.30 & 0.30 & 0.37 & 0.37 & 0.50 & 0.49 \\
\hline horizontal (m) & 0.09 & 0.09 & 0.13 & 0.11 & 0.12 & 0.09 \\
\hline \multicolumn{7}{|l|}{ min angles } \\
\hline ankle $\left(^{\circ}\right)$ & 99 & 100 & 101 & 93 & 101 & 95 \\
\hline knee $\left({ }^{\circ}\right)$ & 88 & 87 & 65 & 60 & 62 & 52 \\
\hline hip $\left(^{\circ}\right)$ & 115 & 112 & 104 & 97 & 58 & 45 \\
\hline \multicolumn{7}{|l|}{ rms differences } \\
\hline orientation $\left({ }^{\circ}\right)$ & - & 1.5 & - & 2.2 & - & 4.6 \\
\hline angles $\left({ }^{\circ}\right)$ & - & 4.9 & - & 9.5 & - & 11.1 \\
\hline lowest point & - & 0.3 & - & 11.3 & - & 20.2 \\
\hline overall score & - & 3.0 & - & 8.6 & - & 13.6 \\
\hline
\end{tabular}

Note: Lowest point RMS difference is of $\mathrm{x}(\mathrm{mm}), \mathrm{y}(\mathrm{mm})$ and time (ms) for the whole body mass centre 
Matching simulations gave RMS differences in trunk orientation angle of between $1^{\circ}$ and $5^{\circ}$, in joint angles of between $5^{\circ}$ and $11^{\circ}$, and in timing and vertical position of the lowest point of less than $9 \mathrm{~ms}$ and $16 \mathrm{~mm}$ (Table 2). Graphics sequences derived from the high speed video data and the matching simulations show close agreement for the landings (Figure 3) and this is reflected in the movement of the mass centre and the time histories of the joint angles and GRFs (Figure 4). There was evidence of co-contraction around the knee and hip at touchdown from the normalized EMG measurements and the initial torque generator activations in the matching simulations (Table 3).

Table 3. Net normalized EMG and matching simulation activations of the ankle, knee and hip extensors and flexors at touchdown

\begin{tabular}{llll}
\hline & $1.2 \mathrm{~m}$ & $1.5 \mathrm{~m}$ & $1.8 \mathrm{~m}$ \\
\hline $\begin{array}{l}\text { Ankle extensors } \\
\text { (medial gastrocnemius, soleus) }\end{array}$ & & & \\
Normalized EMG & 0.168 & 0.141 & 0.119 \\
Matching simulation activation & 0.149 & 0.169 & 0.178 \\
\hline Ankle flexors & & & \\
(tibialis anterior) & & & \\
Normalized EMG & 0.087 & 0.085 & $\mathbf{0 . 0 8 8}$ \\
Matching simulation activation & 0.428 & 0.479 & 0.495 \\
\hline Knee extensors & & & \\
(vastus medialis, rectus femoris) & & & \\
Normalized EMG & 0.169 & 0.162 & 0.159 \\
Matching simulation activation & 0.156 & 0.203 & 0.196 \\
\hline Knee flexors & & & \\
(medial gastrocnemius, & & & \\
semitendinosus) & & & \\
Normalized EMG & 0.219 & 0.320 & 0.329 \\
Matching simulation activation & 0.406 & 0.497 & 0.495 \\
\hline Hip extensors & & & \\
(semitendinosus, gluteus maximus) & & & \\
Normalized EMG & 0.178 & 0.291 & 0.318 \\
Matching simulation activation & 0.115 & 0.134 & 0.133 \\
\hline Hip flexors & & & \\
(rectus femoris) & 0.447 & 0.384 & 0.319 \\
Normalized EMG & 0.199 & 0.209 & 0.161 \\
Matching simulation activation & & & \\
\hline & & & \\
\hline
\end{tabular}

Note: Where there was more than one muscle, the combined EMG was weighted on the basis of relative maximum torque estimated from cross-sectional area and moment arm

The model was then used to determine if it was possible to land successfully without co-contraction, i.e. without activation of the ankle, knee and hip flexor torque generators. These simulations used the same initial conditions as the matching simulations and the extensors were set to a minimal touchdown activation level to produce $1 \mathrm{Nm}$ to take up any slack in the series elastic element. The model could not land successfully from even the lowest height of $1.2 \mathrm{~m}$ without co-contraction, as the knee and hip collapsed before the downward movement of the mass centre could be stopped (see Figure 3 for attempted landing from $1.8 \mathrm{~m}$ ). Without co-contraction the maximum height from which successful landing could be made was $1.05 \mathrm{~m}$ whereas with co-contraction the maximum height was $1.9 \mathrm{~m}$. 
a

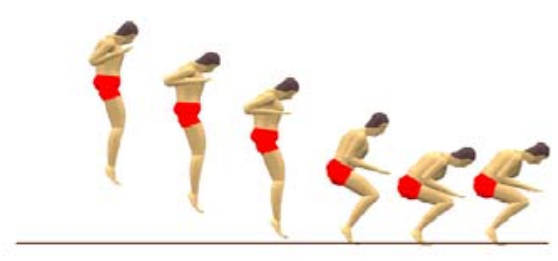

b

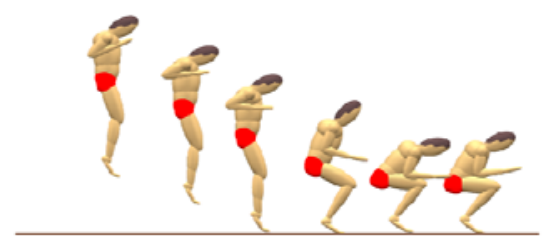

C

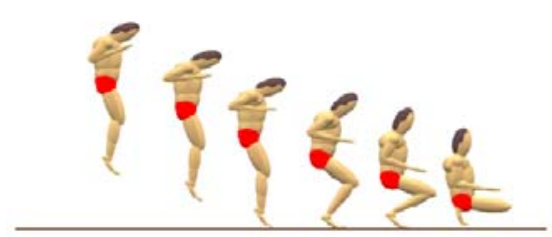

Figure 3. Graphical sequences of drop landings from $1.8 \mathrm{~m}$ : (a) recorded performance, (b) matching simulation and (c) unsuccessful landing without co-contraction.
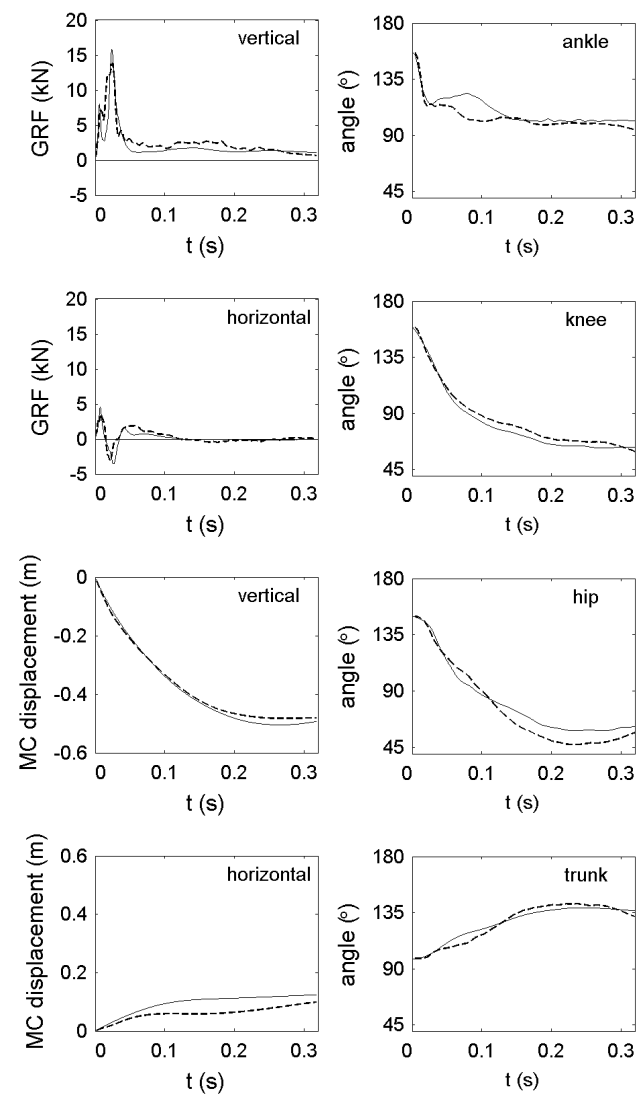

Figure 4. Actual performance and matching simulation results for the $1.8 \mathrm{~m}$ landing showing: ground reaction forces; whole body mass centre displacement; and ankle, knee, hip, orientation angles. (actual performance $=$ solid line; matching simulation $=$ dashed line) . 


\section{DISCUSSION}

The aim of this study was to investigate the extent to which co-contraction is beneficial or necessary in drop landings. A planar 8-segment subject-specific computer simulation model was used to analyse drop landings of an elite athlete from $1.2 \mathrm{~m}, 1.5 \mathrm{~m}$ and $1.8 \mathrm{~m}$. The athlete adopted a strategy with substantial co-activation of flexors and extensors at touchdown. Moreover it was shown that such coactivation was necessary to land successfully from higher than $1.05 \mathrm{~m}$.

Since the results are based on the output of a computer simulation model, the accuracy of such a representation is important. The matching simulations gave agreement with actual performance to within $11^{\circ}$ in RMS joint angles, $5^{\circ}$ in RMS orientation angle and $9 \mathrm{~ms}$ and $16 \mathrm{~mm}$ in timing and vertical position at the lowest point in all three landings. Ground reaction forces were also matched to within 10\% RMS and the global peaks to within $10 \%$ magnitude and $3 \mathrm{~ms}$ timing (Table 2). In the matching simulations maximum vertical depressions of the toe, ball and heel were 10, 30 and $22 \mathrm{~mm}$ respectively which are comparable with a combined heel pad (Pain and Challis, 2001) and training shoe deformation (Alexander \& Bennett, 1989) of $22 \mathrm{~mm}$ for lighter loads than the current landings. Maximum wobbling mass displacements were 20,70 mm and $110 \mathrm{~mm}$ for the shank, thigh and trunk and these compare with $18 \mathrm{~mm}$ and $32 \mathrm{~mm}$ for the shank and thigh for drop landings from $0.4 \mathrm{~m}$ onto the heels measured by Pain and Challis (2006). The larger displacement of the thigh wobbling mass may have been a consequence of the higher impulse to peak force combined with the thigh orientation which allowed greater transverse loading (Challis and Pain, 2008). The amplitude of the trunk wobbling mass was not much greater than the visceral mass oscillations of up to $80 \mathrm{~mm}$ found during rhythmic hopping by Minetti and Belli (1994). Model strength was sufficient but not excessive since the model was able to match the landing from $1.8 \mathrm{~m}$ and give a successful landing from $1.9 \mathrm{~m}$ with cocontraction. At $1.9 \mathrm{~m}$ the maximum height is considerably lower than that calculated by Minetti (1998) who found that athletes should be able to land safely from more than $2.6 \mathrm{~m}$. While it is true that gymnasts do land from such heights in high bar dismounts, the landings are cushioned by a $0.2 \mathrm{~m}$ landing mat. Minetti's result may be a consequence of: the unrealistic assumption that extensors were fully activated at touchdown without any flexor co-contraction, the inclusion of passive joint torque in the model, and use of an over-simplified two segment model.

In this study a common set of stiffness parameters for the wobbling masses were determined for the jumps from $1.2 \mathrm{~m}, 1.5 \mathrm{~m}$ and $1.8 \mathrm{~m}$ and were subsequently used to determine the maximum heights for landings with and without co-contraction. In the maximal landing without co-contraction it could be argued that these stiffness parameters are not appropriate since for low activation levels, wobbling mass stiffness is around five times lower (Wakeling and Nigg, 2001). This would only apply to the first $70-100 \mathrm{~ms}$ of the landing when the extension activations are rising since after this time activations are similar to the co-contraction landings until the mass centre reaches its lowest point after around $250 \mathrm{~ms}$. To investigate the effect of this an additional optimisation for landing with no cocontraction at touchdown was carried out with wobbling mass stiffnesses set at $80 \%$ of their previous values. The result was a simulation without co-contraction that was able to land from $1.07 \mathrm{~m}$ rather than $1.05 \mathrm{~m}$. While this result does not affect the major findings of this paper, it does suggest that allowing wobbling mass stiffness to vary as a function of activation level may be a useful enhancement for future models.

The kinematics of the three landings showed that minimum ankle angle remained approximately constant, minimum knee angle decreased markedly between the $1.2 \mathrm{~m}$ and $1.5 \mathrm{~m}$ landings, and minimum hip angle decreased markedly between the 1.5 and $1.8 \mathrm{~m}$ landings (Table 2). The matching simulations indicated that knee extensor torque reached close to maximum for the lowest landing and 
became maximal for the two higher landings, whilst ankle torque changed marginally and hip torque increased substantially with increasing landing height (Figures 5, 6). Similar to McNitt-Gray (1993), knee extensor torques peaked within the first $50 \mathrm{~ms}$ of landing and this time to peak decreased as landing height increased. The matching simulations followed similar trends to the experimental observations of Zhang et al. (2000), in particular the increasing contribution of the hip extensors with drop height (Figures 5, 6).

a
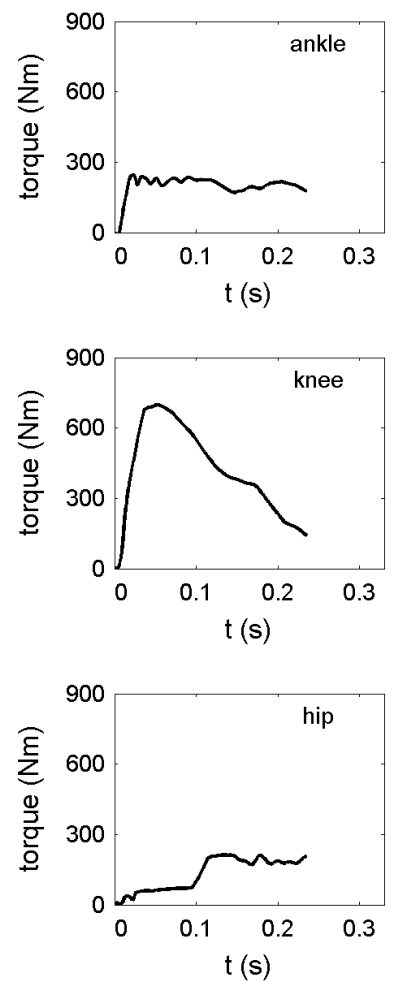

b
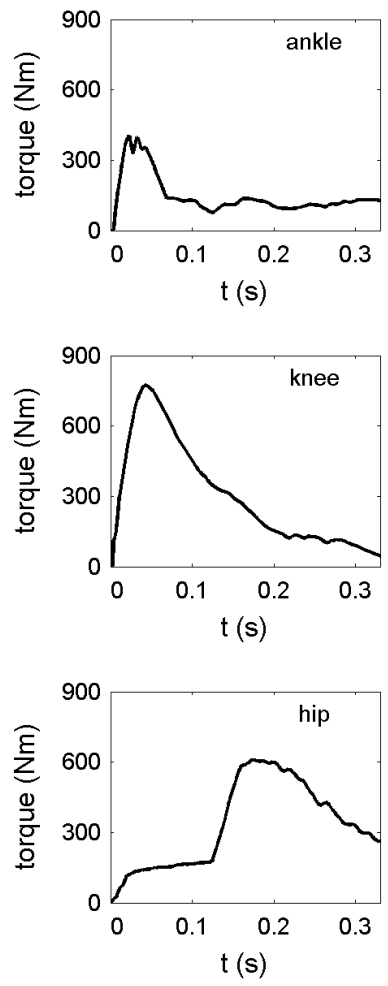

Figure 5. Net joint torques of the ankle, knee and hip from the matching simulations for the drop landings from (a) $1.2 \mathrm{~m}$, and (b) $1.8 \mathrm{~m}$. (Model torque corresponds to the sum of left and right joint torques for the ankle, knee and hip joints).

The simulation results and EMG measurements from this study (Table 3) and previous investigations of drop landings (Whitting et al., 2007; McNitt-Gray et al., 2001, Santello et al., 1998, 2001) and drop jumps (Böhm et al., 2006; Kellis et al., 2003; Arampatzis, 2001) have indicated that flexor co-activity is present at touchdown, even from very modest drop heights of $0.3 \mathrm{~m}$. Indeed, for simulated drops from higher than $1.05 \mathrm{~m}$, it was not possible to arrest the downward velocity of the mass centre without co-contraction. This co-contraction allows some extensor activity at initial contact whilst maintaining minimal net joint torque and joint angular velocity. Despite the evidence for co-contraction at touchdown independent of drop height, the current results suggest that a successful landing without initial co-contraction is theoretically possible from a height of $1.05 \mathrm{~m}$ or less. The main knee flexors are the biarticular gastrocnemius and hamstrings which also serve to extend the ankle and hip joints respectively, and similarly the rectus femoris is both a hip flexor and knee extensor. Therefore some co-contraction at the knee and hip is inevitable if pre-activation of the extensors occurs. On the other hand the mono-articular ankle flexor tibialis anterior also showed co-activation at touchdown in the matching simulations and in the EMG data of previous studies (Santello et al., 1998, 2001; Whitting et al., 2007), indicating that co-contraction is not entirely a consequence of muscle architecture but also of 
chosen technique. Indeed, Russell et al. (2007) found that co-contraction at the knee increased significantly from children to adults and suggested that it is a learned technique that permits adaptability to varied landing tasks.

a
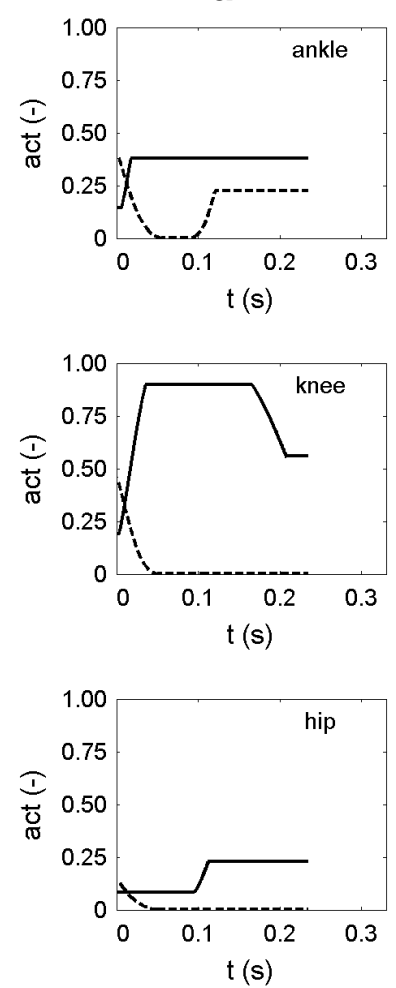

b
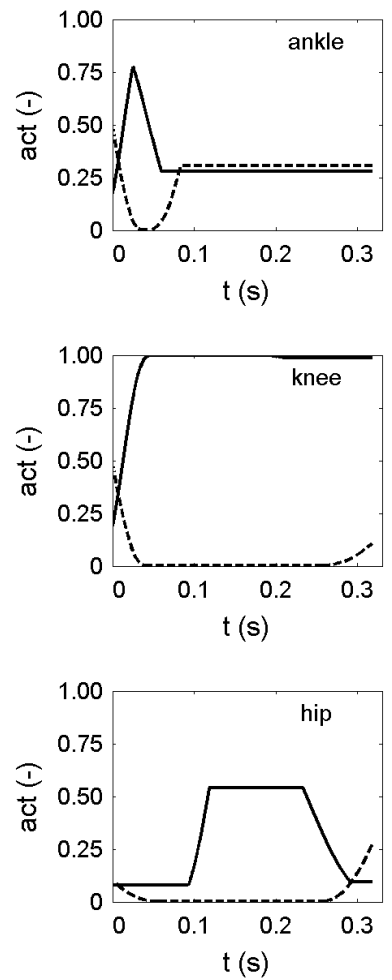

Figure 6. Extensor and flexor activation profiles of the ankle, knee and hip from the matching simulations for the drop landings from (a) $1.2 \mathrm{~m}$, and (b) $1.8 \mathrm{~m}$.

Co-contraction assisted in generating the rapid rise in knee extensor torque required to decelerate the mass centre following initial contact, e.g. for the $1.5 \mathrm{~m}$ landing with co-contraction the torque increased from 0 to $770 \mathrm{Nm}$ (2 legs) within the first $50 \mathrm{~ms}$ of ground contact. Such rapid changes in joint torque are not confined to drop landings. Bobbert et al. (1992) found that net knee torque changed from $100 \mathrm{Nm}$ flexor moment to $200 \mathrm{Nm}$ extensor moment within the first $50 \mathrm{~ms}$ of ground contact in running. How can co-contraction of knee flexors and extensors assist in the production of such rapid changes in net joint torques? After initial contact the knee will flex with increasing angular velocity resulting in increased extensor torque due to the eccentric force-velocity characteristics of muscle (Katz, 1939). At the same time the flexor torque will decrease due to the increasing concentric knee flexor velocity (Hill, 1938). As a consequence the net knee extensor torque will increase rapidly irrespective of any changes in the muscle enervation levels. By simultaneously ramping up extensor activity and ramping off flexor activity this rapid increase in net extensor torque can be further accentuated. The same considerations apply in any activity where rapid changes in net joint torque are required, as for example in running and jumps from a running approach. 


\section{REFERENCES}

Alexander, R.M., Bennet, M., 1989. How elastic is a running shoe? New Scientist 15 July, 45-46.

Arampatzis, A., Schade, F., Walsh, M., Brüggemann, G., 2001. Influence of leg stiffness and its effect on myodynamic jumping performance. Journal of Electromyography and Kinesiology 11, 355 364.

Bobbert, M.F., MacKay, M., Schinkelshoek, D., Huijing, P.A., van Ingen Schenau, G.J., 1986. Biomechanical analysis of drop and countermovement jumps. European Journal of Applied Physiology 54, 566-573.

Bobbert, M.F., van Zandwijk, J.P., 1999. Dynamics of force and muscle stimulation in human vertical jumping. Medicine and Science in Sports and Exercise 31, 303-310.

Bobbert, M.F., Yeadon, M.R., Nigg, B.M., 1992. Mechanical analysis of the landing phase in heel-toe running. Journal of Biomechanics 25, 223-234.

Böhm, H., Cole, G.K., Brüggemann, G., Ruder, H., 2006. Contribution of Muscle Series Elasticity to Maximum Performance in Drop Jumping. Journal of Applied Biomechanics 22, 3-13.

Caldwell, G.E., 1995. Tendon elasticity and relative length: effects on the Hill two-component muscle model. Journal of Applied Biomechanics 11, 1-24.

Challis, J.H., Pain, M.T.G., 2008. Soft tissue motion mediates skeletal loads during impacts. Exercise and Sport Sciences Reviews 36, 71-75.

Clarys, J.P., Marfell-Jones, M.J., 1986. Anthropometric prediction of component tissue masses in the minor limbs of the human body. Human Biology 58, 761-769.

Corana, A., Marchesi, M., Martini, C., Ridella, S., 1987. Minimizing multimodal functions of continuous variables with the "simulated annealing" algorithm. ACM Transactions on Mathematical Software 13, 262-280.

Dapena, J., Chung, C.S., 1988. Vertical and radial motions of the body during the take-off phase of high jumping. Medicine and Science in Sports and Exercise 20, 290-302.

Dempster, W.T., 1955. Space requirements of the seated operator. Wright-Patterson Air Force Base, Ohio WADC-TR: 55-159.

Deporte, E., van Gheluwe. B., 1989. Ground reaction forces in elite high jumping. In Congress Proceedings XII International Congress of Biomechanics. UCLA, Los Angeles.

Freund, H.J., Budingen, H.J., 1978. The relationship between speed and amplitude of the fastest voluntary contractions of human arm muscles. Experimental Brain Research 31, 1-12.

Hill, A.V., 1938. The heat of shortening and the dynamic constraints of muscle. Proceedings of the Royal Society of London, Series B 126, 136-195.

Kane, T. R., Levinson, D. A., 1996. Dynamics online: Theory and implementations with AUTOLEV. OnLine Dynamics, Inc., Sunnyvale, USA.

Katz, B., 1939. The relation between force and speed in muscular contraction. Journal of Physiology 96, 45-64.

Kellis, E., Arabatzi, F., Papadopoulos, C., 2003. Muscle co-activation around the knee in drop jumping using the co-contraction index. Journal of Electromyography and Kinesiology 13, 229-238.

King, M.A., Wilson, C., Yeadon, M.R., 2006. Evaluation of a torque-driven model of jumping for height. Journal of Applied Biomechanics 22, 264-274.

McLean, S.G., Su, A., van den Bogert, A.J., 2003. Development and Validation of a 3-D Model to Predict Knee Joint Loading During Dynamic Movement. Transactions of the ASME 125, 864-874.

McNitt-Gray, J.L., 1993. Kinetics of the lower extremities during drop landings from three heights. Journal of Biomechanics 26, 1037-1046.

McNitt-Gray, J.L., Hester, D.M.E., Mathiyakom, W., Munkasy, B.A., 2001. Mechanical demand and multijoint control during landing depend on orientation of the body segments relative to the reaction force. Journal of Biomechanics 34, 1471-1482. 
Minetti, A.E., Ardigo, L.P., Susta, D., Cotelli, F., 1998. Using leg muscles as shock absorbers: theoretical predictions and experimental results of drop landing performance. Ergonomics 41, 1771-1791.

Minetti, A.E., Belli, G., 1994. A model for the estimation of visceral mass displacement in periodic movements. Journal of Biomechanics 27, 97-101.

Pain, M.T.G., Challis, J. H., 2001. The role of the heel pad and shank soft tissue during impacts: A further resolution of a paradox. Journal of Biomechanics 34, 327-333.

Pain, M.T.G., Challis, J.H., 2004. Wobbling mass influence on impact ground reaction forces: a simulation model sensitivity analysis. Journal of Applied Biomechanics 20, 309-316.

Pain, M.T.G., Challis, J. H., 2006. The influence of soft tissue movement on ground reaction forces, joint torques and joint reaction forces in drop landings. Journal of Biomechanics 39, 119-124.

Panzer, V.P., Wood, G.A., Bates, B.T., Mason, B.R. 1988, Lower extremity loads in landings of elite gymnasts. In: de Groot, G., Hollander, A.P., Huijing, P.A., van Ingen Schenau, G.J. (Eds), Biomechanics XI-B. Amsterdam: Free University Press, pp. 727-735.

Russell, P.J., Croce, R.V., Swartz, E.E., Decoster, L.C., 2007. Knee-muscle activation during landings: developmental and gender comparisons. Medicine \& Science in Sports \& Exercise 39, 159 - 170.

Santello, M., McDonagh, M.J.N., 1998. The control of timing and amplitude of EMG activity in landing movements in humans. Experimental Physiology 83, 857 - 874.

Santello, M., McDonagh, M.J.N., Challis, J.H., 2001. Visual and non-visual control of landing movements in humans. Journal of Physiology 537, 313 - 327.

Wakeling, J.M., Nigg, B.M., 2001. Modification of soft tissue vibration in the leg by muscular activity. Journal of Applied Physiology 90, 412-420.

Whitting, J.W., Steele, J.R., Jaffrey, M.A., Munro, B.J., 2007. Parachute Landing Fall Characteristics at Three Realistic Vertical Descent Velocities. Aviation, Space, and Environmental Medicine 78, 1135 - 1142.

Wilson, C., King, M.A., Yeadon, M.R., 2006. Determination of subject-specific model parameters for visco-elastic elements. Journal of Biomechanics 39, 1883-1890.

Wood, G.A., Jennings, L.S., 1979. On the use of spline functions in data smoothing. Journal of Biomechanics 12, 477-479.

Yeadon, M.R., King, M.A., Wilson, C., 2006. Modelling the maximum voluntary joint torque/angular velocity relationship in human movement. Journal of Biomechanics 39, 476-482.

Yeadon, M.R., 1990. The simulation of aerial movement - II: A mathematical inertial model of the human body. Journal of Biomechanics 23, 67-74.

Zhang, S.N., Bates B.T., Dufek J.S., 2000. Contributions of lower extremity joints to energy dissipation during landings. Medicine \& Science in Sports \& Exercise 32, 812 - 819. 